Dev Neurosci 2018;40:523-533

DOI: $10.1159 / 000497273$
Received: October 9, 2018

Accepted after revision: January 25, 2019

Published online: March 28, 2019

\title{
Chorioamnionitis in Rats Precipitates Extended Postnatal Inflammatory Lymphocyte Hyperreactivity
}

\author{
Tracylyn R. Yellowhair ${ }^{\mathrm{a}}$ Shahani Noor ${ }^{\mathrm{b}}$ Brittney Mares ${ }^{\mathrm{a}}$ Clement Jose $^{\mathrm{a}}$ \\ Jessie C. Newville ${ }^{a, b}$ Jessie R. Maxwell ${ }^{a, b}$ Frances J. Northington ${ }^{c}$ \\ Erin D. Milligan ${ }^{b}$ Shenandoah Robinson ${ }^{d}$ Lauren L. Jantzie ${ }^{a-c}$
}

${ }^{a}$ Department of Pediatrics, University of New Mexico School of Medicine, Albuquerque, NM, USA; ${ }^{b}$ Department of Neurosciences, University of New Mexico School of Medicine, Albuquerque, NM, USA; 'Division of Newborn Medicine, Department of Pediatrics, Johns Hopkins University School of Medicine, Baltimore, MD, USA; ${ }^{\mathrm{d}}$ Division of Pediatric Neurosurgery, Department of Neurosurgery, Johns Hopkins University School of Medicine, Baltimore, MD, USA

\section{Keywords}

Preterm birth - Tumor necrosis factor $a \cdot$ Immune reactivity · Placenta $\cdot$ Peripheral blood mononuclear cells $\cdot$ CXCL1

\begin{abstract}
Preterm birth is an important cause of perinatal brain injury (PBI). Neurological injury in extremely preterm infants often begins in utero with chorioamnionitis (CHORIO) or inflammation/infection of the placenta and concomitant placental insufficiency. Studies in humans have shown dysregulated inflammatory signaling throughout the placental-fetal brain axis and altered peripheral immune responses in children born preterm with cerebral palsy (CP). We hypothesized that peripheral immune responses would be altered in our wellestablished rat model of CP. Specifically, we proposed that isolated peripheral blood mononuclear cells (PBMCs) would be hyperresponsive to a second hit of inflammation throughout an extended postnatal time course. Pregnant SpragueDawley dams underwent a laparotomy on embryonic day 18 (E18) with occlusion of the uterine arteries (for $60 \mathrm{~min}$ ) followed by intra-amniotic injection of lipopolysaccharide (LPS,
\end{abstract}

$4 \mu \mathrm{g} / \mathrm{sac}$ ) to induce injury in utero. Shams underwent laparotomy only, with equivalent duration of anesthesia. Laparotomies were then closed, and the rat pups were born at E22. PBMCs were isolated from pups on postnatal day 7 (P7) and P21, and subsequently stimulated in vitro with LPS for 3 or $24 \mathrm{~h}$. A secreted inflammatory profile analysis of conditioned media was performed using multiplex electrochemiluminescent immunoassays, and the composition of inflammatory cells was assayed with flow cytometry (FC). Results indicate that CHORIO PBMCs challenged with LPS are hyperreactive and secrete significantly more tumor necrosis factor a (TNFa) and C-X-C chemokine ligand 1 at P7. FC confirmed increased intracellular TNFa in CHORIO pups at P7 following LPS stimulation, in addition to increased numbers of CD $11 \mathrm{~b} / \mathrm{c}$ immunopositive myeloid cells. Notably, TNFa secretion was sustained until P21, with increased interleukin 6 , concomitant with increased expression of integrin $\beta 1$, suggesting both sustained peripheral immune hyperreactivity and a heightened activation state. Taken together, these data indicate that in utero injury primes the immune system and augments enhanced inflammatory signaling. The insidious effects of primed peripheral immune cells may compound
KARGER

(C) 2019 S. Karger AG, Basel

E-Mail karger@karger.com

www.karger.com/dne
Lauren L. Jantzie

Division of Neonatal-Perinatal Medicine, Department of Pediatrics and Department of Neurology, Johns Hopkins University School of Medicine Baltimore, MD 21287 (USA)

E-Mail LJantzie@jhmi.edu 
$\mathrm{PBI}$ secondary to $\mathrm{CHORIO}$ and/or placental insufficiency, and thereby render the brain susceptible to future chronic neurological disease. Further understanding of inflammatory mechanisms in PBI may yield clinically important biomarkers and facilitate individualized repair strategies and treatments.

(c) 2019 S. Karger AG, Basel

\section{Introduction}

In the USA and worldwide, prematurity is a major cause of infant mortality and long-term disability in children [1]. Survivors of very preterm birth can have numerous neurological disorders and cognitive impairment, including cerebral palsy (CP), epilepsy, intellectual disability, impaired sensory processing, and attentional disorders [2-4]. Epidemiological, clinical, and preclinical studies support a placental-fetal brain axis in neurological development, with alterations or disruptions in this axis leading to brain injury [2, 5-7]. Chorioamnionitis (CHO$\mathrm{RIO})$ is the most common abnormality found in placentas from very preterm infants and a principle cause of preterm birth [8-11]. Defined by inflammation and hypoxiaischemia (HI), CHORIO disrupts the maternal-placental interface and directly impacts the fetal microenvironment $[12,13]$. It is well established that injuries during these critical periods of development have long-term effects on growth, metabolism, cognitive function, motor performance, and inflammatory response $[5,6,12,14-16]$.

Changes in the intrauterine microenvironment, and subsequent fetal and neonatal events, impact development and life-long susceptibility to illness. Indeed, environmental stressors can negatively affect the development of fundamental physiological processes, including those of the immune and central nervous systems. CHORIO is a significant risk factor for CP in term, near-term, and preterm infants $[8,17-22]$. Perinatal inflammatory responses have been implicated in the pathophysiology of CP $[14,23,24]$. A fetal inflammatory response syndrome (FIRS), the fetal equivalent of systemic inflammatory response syndrome (SIRS), is frequently present in neonates born as a result of spontaneous preterm labor secondary to CHORIO [25-28].

Like the central nervous system, the fetal immune system develops and matures over the course of gestation [26]. Similar to neural cells, fetal and neonatal leukocytes are uniquely responsive to their environment $[26,29]$. Indeed, delineation of leukocyte responses following injury may serve as an important clinical and scientific biomarker. Minimizing the impact of perinatal brain injury (PBI) due to preterm birth is dependent on the successful identification of critical pathways essential to the developmental programs amongst neural-immune cells in the placental-fetal brain axis [30]. While the interactions between innate and adaptive immune responses following PBI are relatively unknown, human studies have shown that preterm children with $\mathrm{CP}$ have altered inflammatory responses at school age [14]. Specifically, peripheral blood mononuclear cells (PBMCs) from children with $\mathrm{CP}$ are hyperresponsive to lipopolysaccharide (LPS) stimulation compared to age-matched typically developing preterm controls. Previously, we found a robust FIRS in our rat model of CP secondary to placental inflammation and insufficiency, along with lasting cognitive and motor impairment, and significant alterations in the placental-fetal brain axis [25, 31-33]. Thus, given that developmental plasticity is altered by perinatal injury and may have longterm effects on the inflammatory responses of circulating leukocytes, we hypothesized that peripheral immune responses would be altered through a prolonged period of development in our rat model of CP.

\section{Materials and Methods}

\section{Animals}

All procedures were performed consistent with National Research Council guidelines, and with the approval of the Institutional Animal Care and Use Committee at the University of New Mexico Health Sciences Center. ARRIVE guidelines were followed [34].

\section{Prenatal Insult}

Pregnant Sprague-Dawley rat dams underwent abdominal laparotomy on embryonic day 18 (E18), consistent with previous reports $[25,31-33,35-38]$. To induce prenatal injury similar to CHORIO, bilateral uterine arteries were transiently occluded for $60 \mathrm{~min}$ to induce placental insufficiency, followed by an intra-amniotic injection of LPS 0111:B4 (4 $\mu \mathrm{g} / \mathrm{sac}$; Sigma-Aldrich, St. Louis, MO, USA) as previously published [25, 30-33]. Laparotomies were closed, and the rat pups were born at term on E22. Sham dams underwent laparotomy with equivalent exposure to anesthesia. Male and female pups were used and randomly assigned to all outcome measures, and they represented the offspring from at least 4 different dams per condition. Previously, we published the placental pathology with robust neutrophilia and cytokine levels consistent with histological CHORIO, FIRS, neuroinflammatory responses, as well as MRI outcome and the long-term cognitive and motor functional abnormalities in this model [25, 31-33].

\section{PBMC Isolation}

PBMCs from sham or CHORIO pups were isolated on postnatal day 7 (P7) and P21 using a Ficoll gradient separation [14]. Specifically, venous blood was collected from the right atrium in pyrogen-free, heparinized, K2 EDTA vacutainer tubes (Becton Dick- 


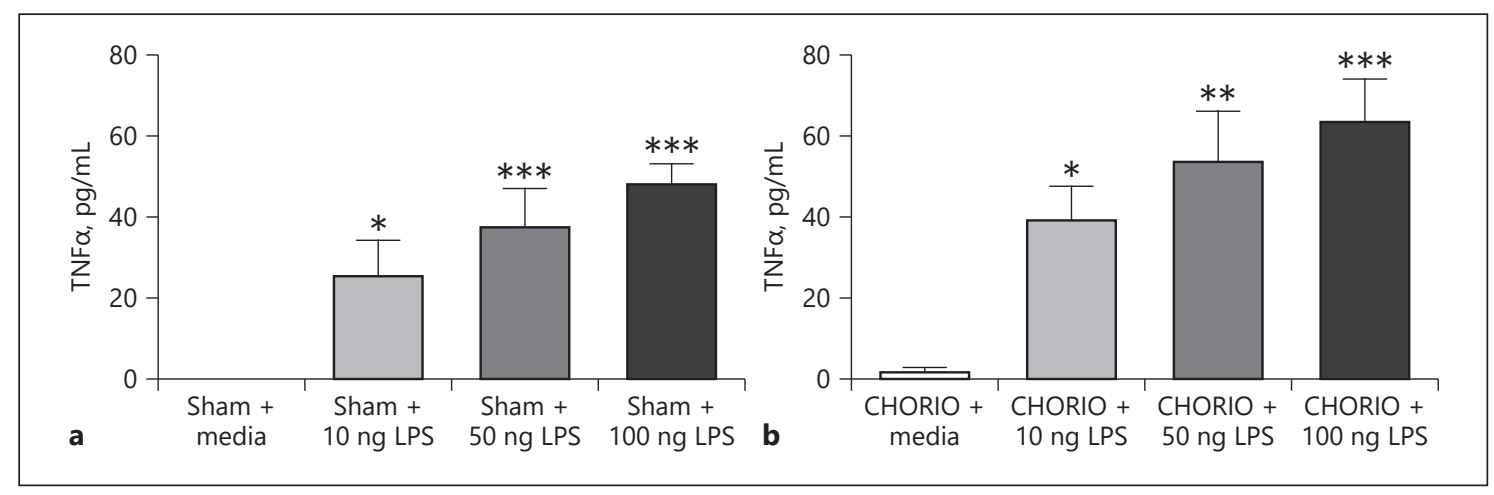

Fig. 1. LPS induces dose-responsive increases in TNFa. Peripheral blood mononuclear cells isolated from postnatal day 21 pups were stimulated with control or LPS $(10,50$, and $100 \mathrm{ng} / \mathrm{mL})$ for $24 \mathrm{~h}$ in sham (a) and CHORIO (b) pups. ${ }^{*} p<0.05,{ }^{* *} p<0.01,{ }^{* * *} p<0.001$.

inson, Franklin Lakes, NJ, USA). Blood was pooled from P7 pups but not P21 pups. Two milliliters of blood plus $2 \mathrm{~mL}$ RPMI 1640 media (Gibco, Waltham, MA, USA), were then added to a $15-\mathrm{mL}$ conical tube with mixing by inversion. The blood mixture was layered on $3 \mathrm{~mL}$ of well-mixed Ficoll-Paque Plus 1084 (GE Healthcare, Chicago, IL, USA) media, and then centrifuged at $400 \mathrm{~g}$ for $30 \mathrm{~min}$ at room temperature with the centrifuge brake in the "off" position. Using a sterile pipette, the upper layer containing plasma and platelets was drawn off, leaving the mononuclear cell layer undisturbed at the interface. Mononuclear cells were then transferred to a sterile centrifuge tube using a sterile pipette, and 3 volumes (approx. $6 \mathrm{~mL}$ ) RPMI media were added. Cells were suspended by gently drawing them in and out of a pipette and then centrifuged at $400 \mathrm{~g}$ for $10 \mathrm{~min}$ at room temperature with the centrifuge brake on. Subsequently, supernatant was removed, and the cells were resuspended in $6 \mathrm{~mL}$ RPMI media. After an additional round of centrifugation as described above, supernatant was discarded, and the cell pellet resuspended in 6-8 mL RPMI media and prepared for plating.

\section{PBMC Treatment with LPS}

PBMCs at P7 or P21 were plated in $3.5-\mathrm{cm}$ culture dishes at a density of $2 \times 10^{6}$ cells per dish $\left(1 \times 10^{6}\right.$ cells $/ \mathrm{mL}, 2 \mathrm{~mL}$ each). PBMCs were then stimulated without or with LPS $(10,50$, or 100 $\mathrm{ng} / \mathrm{mL}$ ) for 3 or $24 \mathrm{~h}$ and the supernatants collected, consistent with prior reports $[14,39]$. Each experimental condition was performed in triplicate. Notably, treatment of PBMCs from both CHORIO and sham pups with differing doses of LPS yielded a dose response of TNFa secretion (Fig. 1). Given the robustness of the response, and consistent with previous reports, $100 \mathrm{ng} / \mathrm{mL}$ of LPS was used for all subsequent experiments [40-42].

\section{Multiplex Electrochemiluminescent Immunoassay}

A secreted cytokine and chemokine profile analysis was performed on supernatants from cultured PBMCs ( $n=6-7 /$ group) using a $\mathrm{V}$-plex rat proinflammatory panel for $\mathrm{TNF}$ a, interleukin (IL)-1 $\beta$, C-X-C chemokine ligand 1 (CXCL1) and IL-6 (MesoScale Discovery, Gaithersburg, MD, USA). Specifically, conditioned media was loaded (diluted 1:4) in duplicate on a 96-well plate, consistent with the manufacturer's specification and also numerous prior preclinical and clinical studies [25, 43-48]. Plates were read on a Quickplex SQ 120 Imager. This system has high content validity and an interassay variation of $<12 \%$ in our laboratory.

\section{Flow Cytometry}

PBMCs from CHORIO and sham groups were isolated and plated as described above. All antibodies were purchased from Thermo Fisher Scientific-eBioscience (Waltham, MA, USA) and were used at $0.125-0.5 \mu \mathrm{g}$ per $1 \times 10^{6}$ cells, as recommended by the manufacturer. Four pups per condition (sham or CHORIO) were used for each experiment, resulting in a total of 8 pups at both P7 and P21. Cells for each condition were plated in 2 replicate wells. Cells from one of the replicate wells were used for the surface staining of CD45 (common leukocyte marker), CD11b/c (integrin $\alpha-\mathrm{M}$, pan marker for myeloid cells), MHC2 (immune activation marker), ED2-like antigen (rat macrophage marker, HIS36), and CD29 (integrin $\beta 1$ ). Cells from other replicate wells were used for surface staining of CD45 and $\mathrm{CD} 11 \mathrm{~b} / \mathrm{c}$, followed by intracellular staining for the cytokine TNFa. Cells that were assayed for intracellular cytokine detection were treated with a $2 \mu \mathrm{L} / \mathrm{mL}$ protein transport inhibitor cocktail (containing brefildin A and monensin; Thermo Fisher Scientific-eBioscience) that was added simultaneously with media or LPS at the beginning of the cultures. The protein transport inhibitor cocktail inhibits the intracellular protein secretory/transport pathway, resulting in the accumulation of secreted proteins/cytokines in the lumen of the endoplasmic reticulum and in the Golgi apparatus which can be detected by intracellular staining and flow cytometric analysis [49].

Staining for surface antigens and intracellular cytokines was conducted as described in Noor et al. [50]. Briefly, following $24 \mathrm{~h}$ of stimulation with LPS or media, cells were transferred into separate FACS tubes (BD Falcon ${ }^{\mathrm{TM}}$, Becton Dickinson) and pelleted by centrifugation at $300 \mathrm{~g}$ for $10 \mathrm{~min}$ at $4{ }^{\circ} \mathrm{C}$, with the supernatant discarded. Cells were then resuspended in $1 \times$ PBS (without calcium and magnesium; Sigma-Aldrich) and stained with Viability Dye eFluor ${ }^{\circledR} 450$ (Thermo Fisher Scientific-eBioscience) for 30 min, washed with FACS buffer ( $1 \times$ PBS containing $1.0 \%$ BSA and $1 \mathrm{~mm}$ EDTA). Cells were then incubated with a saturating solution of Fc block (BD Biosciences, San José, CA, USA) for $10 \mathrm{~min}$, followed by staining with fluorochrome-conjugated antibodies against surface antigen or appropriate isotype controls for $30 \mathrm{~min}$. 
All of these steps were conducted in the dark on ice. Following surface antibody staining, cells were washed and resuspended in $250 \mu \mathrm{L}$ FACS buffer, and then passed through a $40-\mu \mathrm{m}$ cell strainer immediately prior to analysis to avoid cell clumping.

For intracellular staining of TNFa, cells were washed with PBS and stained with viability dye and surface markers (CD45 and $\mathrm{CD} 11 \mathrm{~b} / \mathrm{c}$ ), as described above. Cells were then fixed with $4 \%$ PFA (Sigma-Aldrich) for $20 \mathrm{~min}$ at room temperature, washed with FACS buffer and permeabilized with $0.3 \%$ saponin (Sigma-Aldrich) in FACs buffer, followed by incubation with anti-rat TNFa for 40 min on ice in the dark. Cells were then washed in saponinFACs buffer, resuspended in FACS buffer, and then proceeded to flow cytometer data acquisition, as described previously $[32,50]$.

For flow cytometry (FC) analysis at P7, UltraComp eBeads (Thermo Fisher Scientific-eBioscience) were used for generating compensation controls; for P21 FC, blood leukocytes with single fluorochrome stains were used for compensation controls. For P21 FC analysis, viability dye was not included; live cells were identified by their size and granularity. Data were acquired using the BD LSR Fortessa cell analyzer (BD Biosciences) and analyzed using FlowJo software v8.7.4 (FlowJo LLC, Ashland, OR, USA). Cells were gated first on size and granularity (FSC vs. SSC), followed by gating on single cells (SSC-A vs. SSC-H and FSC-A vs. FSC-H). Viable (verified by viability dye staining) and CD45-positive (CD45+) cells were identified, as described before $[43,50]$. To identify myeloid cells, only CD45+ cells were analyzed for CD11b/c+ expression. $\mathrm{CD} 45+\mathrm{CD} 11 \mathrm{~b} / \mathrm{c}+$ cells were then further analyzed for MHC2, ED2-like antigen, CD29, or TNFa expression. Mean fluorescence intensity (MFI) was measured.

\section{Statistical Analyses}

Data are represented as mean \pm standard error of the mean (SEM). Parametric statistical differences between 2 groups were compared with Student's $t$ test, and between 3 groups with a oneway ANOVA with Tukey's post hoc correction. $p<0.05$ was considered statistically significant.

\section{Results}

In utero Insult Yields Altered Inflammatory Responses at $P 7$

Beginning on P7, we isolated PBMCs from pups exposed to sham conditions or in utero CHORIO insult. The levels of TNFa in the supernatant of nonstimulated PBMCs from sham and CHORIO pups were comparable after $3 \mathrm{~h}(0.22 \pm 0.7$ vs. $0.30 \pm 0.06 \mathrm{pg} / \mathrm{mL}$, respectively $)$, although a baseline difference in the levels of IL-6 was detected with CHORIO PBMCs secreting 2.6-fold more IL-6 than sham PBMCs at $3 \mathrm{~h}(p<0.001)$. LPS stimulation of the PBMCs resulted in significant increases of TNFa in the supernatants of both groups (sham: $0.22 \pm 0.7$ vs. $11.02 \pm 0.7 \mathrm{pg} / \mathrm{mL}$; CHORIO: $0.30 \pm 0.06$ vs. $26.66 \pm 6.8$ $\mathrm{pg} / \mathrm{mL}, p<0.001$ for both). However, CHORIO PBMCs had significantly higher levels of secreted TNFa in response to LPS stimulation than the PBMCs from the sham pups (Fig. 2a) as well as significantly increased CXCL1 secretion (Fig. 2b). No additional changes in IL-6 levels were observed with LPS challenge. These increased responses compared to sham demonstrates enhanced immune reactivity. This pattern held at $24 \mathrm{~h}$ of LPS stimulation, with CHORIO PBMCs continuing to secrete more TNFa and CXCL1 than sham-stimulated PBMCs (Fig. $2 \mathrm{c}-\mathrm{d}$ ), but not more IL-6 (114 vs. $91 \mathrm{pg} / \mathrm{mL}, p>$ $0.05)$. Interestingly, by $24 \mathrm{~h}$, the levels of TNFa in the supernatant of nonstimulated PBMCs from sham and CHORIO pups were significantly different. In this nonstimulated condition, TNFa secretion was increased by $84 \%$ in CHORIO pups compared to sham controls (Fig. 2e, $p<0.05$ ). Furthermore, FC analyses confirmed increased intracellular TNFa in CHORIO PBMCs compared to sham PBMCs (Fig. $2 \mathrm{f}-\mathrm{g}$ ). Together, these data indicate that the PBMCs from the CHORIO pups were hyperreactive in response to a second LPS stimulus during the first postnatal week.

To test whether differences in cytokine secretion and PBMC hyperreactivity were a result of fundamental changes in white blood cell populations after CHORIO, we performed FC for common cell-surface, cell-specific markers. At baseline and without LPS stimulation, CHORIO PBMCs were defined by significantly higher percentages of CD11b/c- and ED-2/CD163-expressing cells (Fig. 3a, b), indicating increased numbers of circulating myeloid and mature macrophages at $\mathrm{P} 7$ in CHORIO pups compared to sham pups. However, at baseline, there were no differences in integrin $\beta 1$, a marker of activation (Fig. 3c). Interestingly, LPS stimulation sustained the increase in CD11b/c+ cells in CHORIO pups compared to sham pups (Fig. 3d). This alteration, however, occurred in the absence of any difference in MHC2 or integrin $\beta 1$ expression (Fig. 3e, f). Taken together, these data show that CHORIO changes the population of white blood cells and that a secondary hit of LPS sustains the number of myeloid cells when compared to nonstimulated LPS controls.

\section{In utero Insult Yields Sustained Changes in}

\section{Inflammatory Responses at P21}

After establishing changes in peripheral inflammatory reactivity at $\mathrm{P} 7$, or 2 weeks after in utero insult, we determined whether changes in immune cell reactivity and response had been sustained. Thus, we assessed PBMCs for the secretion of proinflammatory cytokines and chemokines at P21, 4 weeks after CHORIO, equivalent to toddler age in humans. Similar to what was observed at P7, sham and CHORIO PBMCs secreted similar levels of TNFa in the absence of LPS $(0.14 \pm 0.07$ vs. $0.16 \pm 0.12$ 


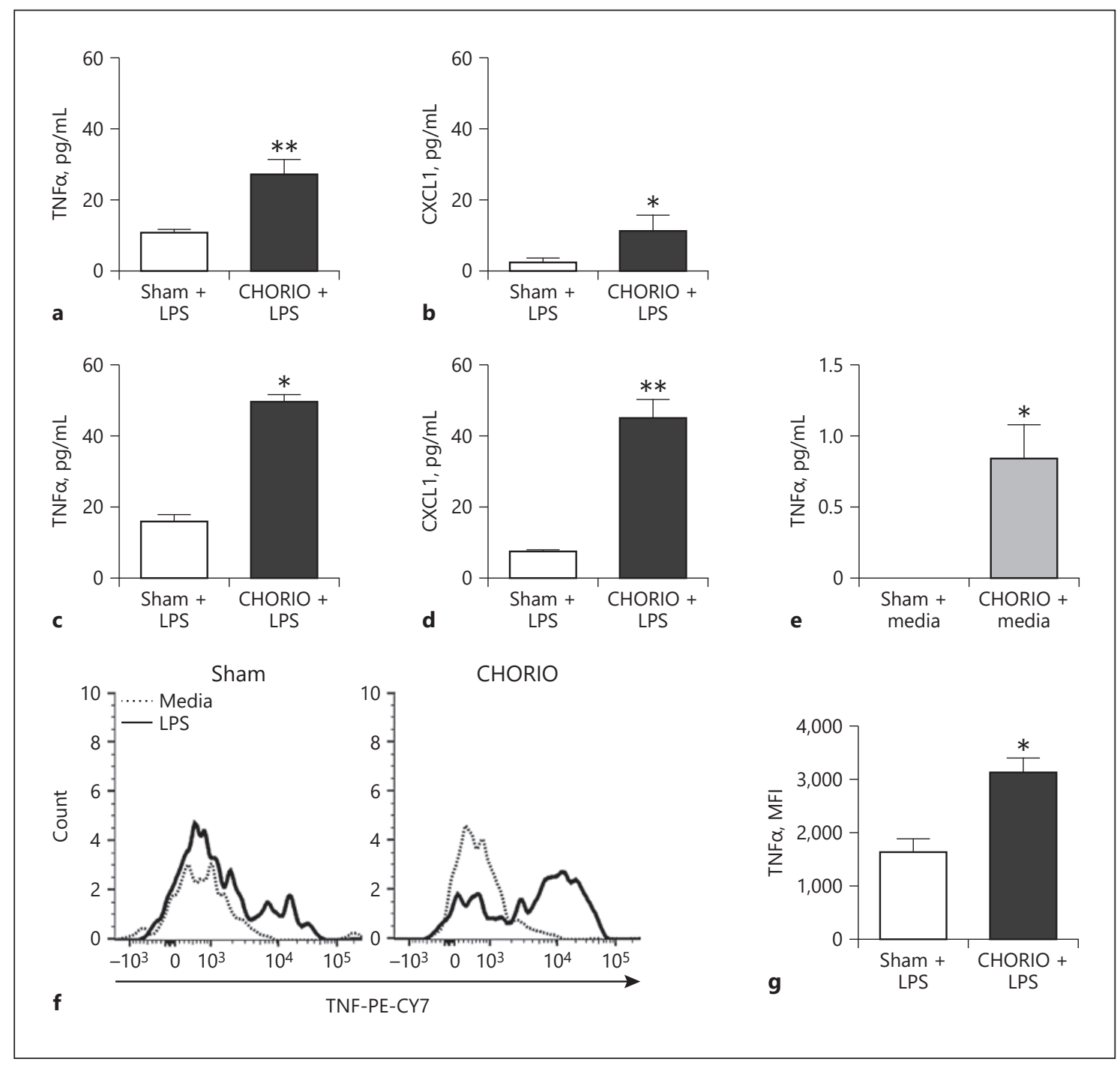

Fig. 2. CHORIO peripheral blood mononuclear cells (PBMCs) are primed and augment proinflammatory cytokine secretion following LPS stimulation. PBMCs were isolated from postnatal day 7 sham or CHORIO pups and stimulated with control or LPS for $3 \mathrm{~h}(\mathbf{a}, \mathbf{b})$ or $24 \mathrm{~h}(\mathbf{c}-\mathbf{g})$. Secreted levels of TNFa (a) and CXCL1 (b) were significantly increased in CHORIO PBMCs challenged with LPS compared to sham control PBMCs. At $24 \mathrm{~h}$, CHORIO PBMCs also secreted more TNFa (c) and CXCL1 (d) than sham PBMCs in response to LPS challenge. e Notably, CHORIO PBMCs secreted more TNFa in the absence of LPS challenge and at baseline when compared to sham cells. f, $\mathbf{g}$ Flow cytometry confirmed increased intracellular TNFa in LPS-stimulated CHORIO PBMCs. ${ }^{*} p<0.05$, ** $p<0.01$. $\mathrm{pg} / \mathrm{mL}$ ). Additionally, both sham and CHORIO cells responded to LPS by increasing TNFa (sham: $0.14 \pm 0.07$ vs. $10.44 \pm 2.3 \mathrm{pg} / \mathrm{mL}$ TNFa; CHORIO: $0.16 \pm 0.12$ vs. $23.32 \pm 3.8 \mathrm{pg} / \mathrm{mL}, p<0.001$ for both). Notably, in the presence of LPS for $3 \mathrm{~h}$, PBMCs from P21 CHORIO rats hypersecreted TNF $\alpha$ and IL-6, compared to sham PBMCs, but not CXCL1 (Fig. 4a-c). This effect was also observed when the PBMCs were stimulated with LPS for $24 \mathrm{~h}$ (Fig. $4 \mathrm{~d}-\mathrm{f}$ ). Interestingly, by $24 \mathrm{~h}$, the levels of TNFa in the supernatant of nonstimulated PBMCs from sham and CHORIO pups were also significantly different $(0.16 \pm$ 0.07 vs. $0.99 \pm 0.13 \mathrm{pg} / \mathrm{mL}, p<0.001$, Fig. 4 g), confirming a long-term change in PBMC secretion of TNFa and immune reactivity even at baseline. FC performed on P21 cells corroborated a trend to increased intracellular TNFa (Fig. $4 \mathrm{~h}, p=0.06$ ). These data indicate persistent peripheral hyperimmune reactivity following CHORIO and in response to LPS stimulation. 


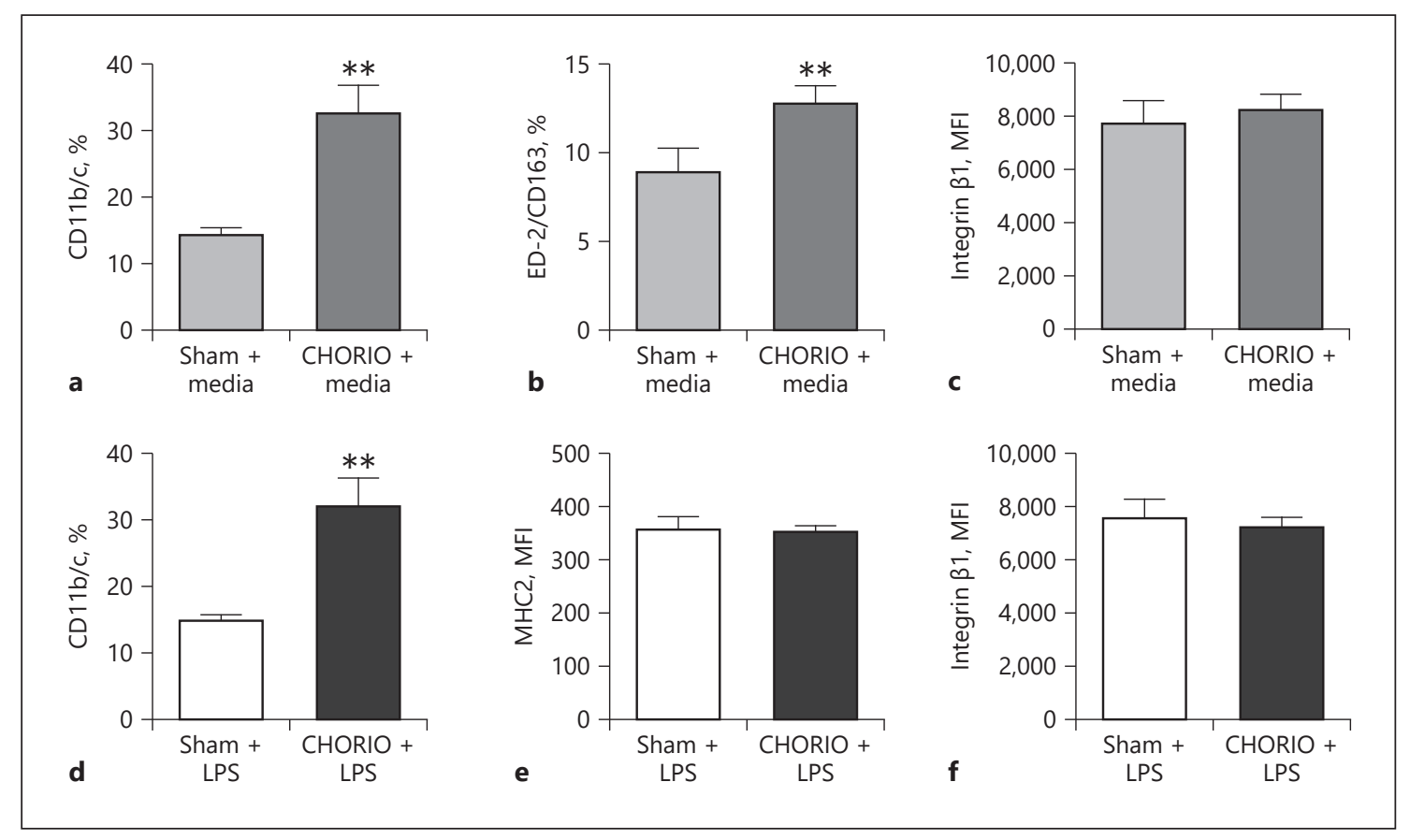

Fig. 3. CHORIO increases circulating myeloid cells. Peripheral blood mononuclear cells (PBMCs) isolated from postnatal day 7 pups were stimulated with control or LPS $(100 \mathrm{ng} / \mathrm{mL})$ for $24 \mathrm{~h}$. Flow cytometry analysis was used to identify the proportions of myeloid cells and their activation levels. a Notably, proportions of viable (identified by size, granularity and viability dye staining) myeloid (CD45+CD11b/c+) cells were increased in the PBMCs of CHORIO pups compared to sham controls at baseline. b Similarly, the proportion of cells showing positive expression for the mature macrophage marker (ED-2/CD163-like antigen) among

Next, we examined whether PBMC hyperreactivity was associated with changes in immune cell markers using FC with surface antigen staining. Interestingly, despite changes in proinflammatory secretion, we found similar levels of CD $11 \mathrm{~b} / \mathrm{c}$ cells in CHORIO and sham cells treated with LPS (Fig. 5a), as well as an equivalent expression of MHC2 (Fig. 5b). However, integrin $\beta 1$ (CD29) was significantly elevated on LPS-stimulated CHORIO PBMCs compared to sham-stimulated cells, consistent with an increased activation state (Fig. 5c). Notably, baseline levels of integrin $\beta 1$ at $\mathrm{P} 21$ were equivalent in sham and CHORIO cells (Fig. 5d).

\section{Discussion}

Preterm infants exposed to intrauterine inflammation are at an increased risk of neurodevelopmental disorders, and adverse outcomes are more strongly associated with viable myeloid cells even without LPS stimulation was also increased in CHORIO pups compared to sham controls. $\mathrm{c}$ When viable myeloid cells at baseline were further analyzed for the adhesion molecule integrin $\beta 1$, however, there were no differences in expression (mean fluorescence intensity, MFI), indicative of equivalent activation. d With LPS challenge, proportions of $\mathrm{CD} 11 \mathrm{~b} / \mathrm{c}+$ cells remained increased compared to sham PBMCs stimulated with LPS. However, no differences in MFI for MHC2 (e) or integrin $\beta 1$ (f) were observed. ${ }^{* *} p<0.01$.

a combination of antenatal and postnatal inflammation than either circumstance alone [51]. In this report, we provide the first evidence that levels of TNFa, CXCL1, and IL-6 released from LPS-stimulated PBMCs are significantly higher in term-equivalent P7 and toddlerequivalent P21 rats exposed to prenatal placental inflammation and insufficiency concomitant with acute changes in inflammatory cell composition and enduring alterations in their systemic inflammatory response. Together, these data suggest that rats with in utero injury have sustained peripheral immune hyperreactivity (SPIHR). These data corroborate reports on preterm children with CP [14] and our own previous reports of elevated serum proinflammatory cytokines, enhanced inflammatory signal transduction through the maternalplacental-fetal axis, and CP-like motor phenotypes in this model $[25,32]$. Indeed, immune plasticity altered by in utero insults may have long-term effects on the inflammatory responses of circulating leukocytes, which may 


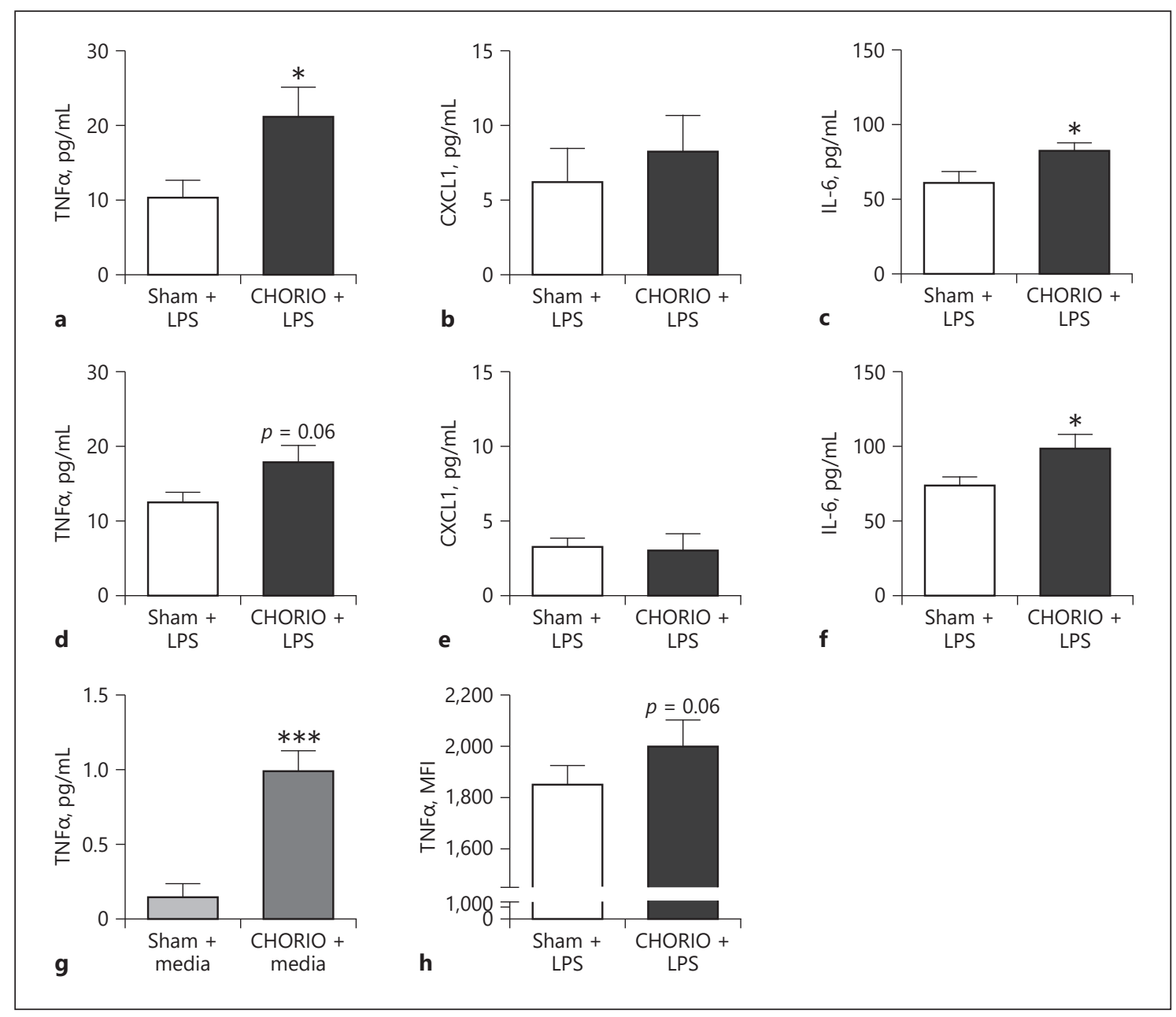

Fig. 4. CHORIO-induced hyperactivation of peripheral blood mononuclear cells (PBMCs) is sustained until postnatal day 21 (P21). PBMCs were isolated from P21 sham or CHORIO pups and stimulated with control or LPS for $3 \mathrm{~h}(\mathbf{a}-\mathbf{c})$ or $24 \mathrm{~h}(\mathbf{d}-\mathbf{h})$. Secreted levels of TNFa (a) and IL-6 (c) were significantly increased in CHORIO PBMCs challenged with LPS compared to sham control PBMCs, but the CXCL1 level remained unchanged. At $24 \mathrm{~h}, \mathrm{CHO}-$

serve as a biomarker of persistent or prior neuroinflammation and brain injury $[52,53]$. Notably, preterm newborns that have elevated levels of biomarkers of systemic inflammation on 2 occasions 1 week apart are at a higher risk of brain injury and impaired neurodevelopment [47, $48,51,54]$. Thus, the insidious effects of primed peripheral immune cells may compound PBI secondary to CHORIO and increase susceptibility to future chronic onset neurological diseases.

The mechanisms for how remote maternal infections or CHORIO facilitate PBI are unknown. Numerous studies have reported that higher levels of proinflammatory
RIO PBMCs also secreted more TNFa (d) and IL-6 (f) than sham PBMCs in response to LPS challenge. $\mathbf{g}$ CHORIO P21 PBMCs secreted more TNF $\alpha$ in the absence of LPS challenge and at baseline compared to sham cells. h Flow cytometry confirmed increased intracellular TNFa in LPS-stimulated CHORIO PBMCs. ${ }^{*} p<0.05$, ${ }^{* * *} p<0.001$. cytokines such as TNFa in the amniotic fluid, plasma, and umbilical cord blood are associated with $\mathrm{CP}$ in children who are born preterm $[14,55-59]$. Circulating proinflammatory cytokines can directly induce damage [56]. Similarly, immune cells can also be directly involved in injury [60-62]. The immature brain expresses CXC chemokines that promote cellular infiltration $[25,32,56,60]$, and lymphocytes expressing TNFa and IL- 6 have been identified within lesions in the preterm human brain. Undoubtedly, the role of TNFa is multifactorial, as it is secreted by numerous cells, including microglia and macrophages in the periphery [63]. T helper cells, including 
Fig. 5. CHORIO-induced hyperactivation of myeloid cells continues at least until postnatal day 21 (P21). Flow cytometry analysis of peripheral blood mononuclear cells (PBMCs) isolated from P21 pups revealed equivalent proportions of viable myeloid (CD45+CD11b/c+) cells in PBMCs from sham and CHORIO pups following LPS stimulation (a), and similar MHC2 mean fluorescent intensity (MFI) (b). c However, when viable myeloid cells from LPS-stimulated groups were further analyzed for the adhesion molecule, integrin $\beta 1$, CHORIO cells challenged with LPS had significantly increased expression (MFI) compared to sham cells challenged with LPS, indicative of enhanced activation. d Levels of integrin $\beta 1$, and thus activation, are similar between sham and CHORIO cells at baseline. ${ }^{*} p<0.05$.

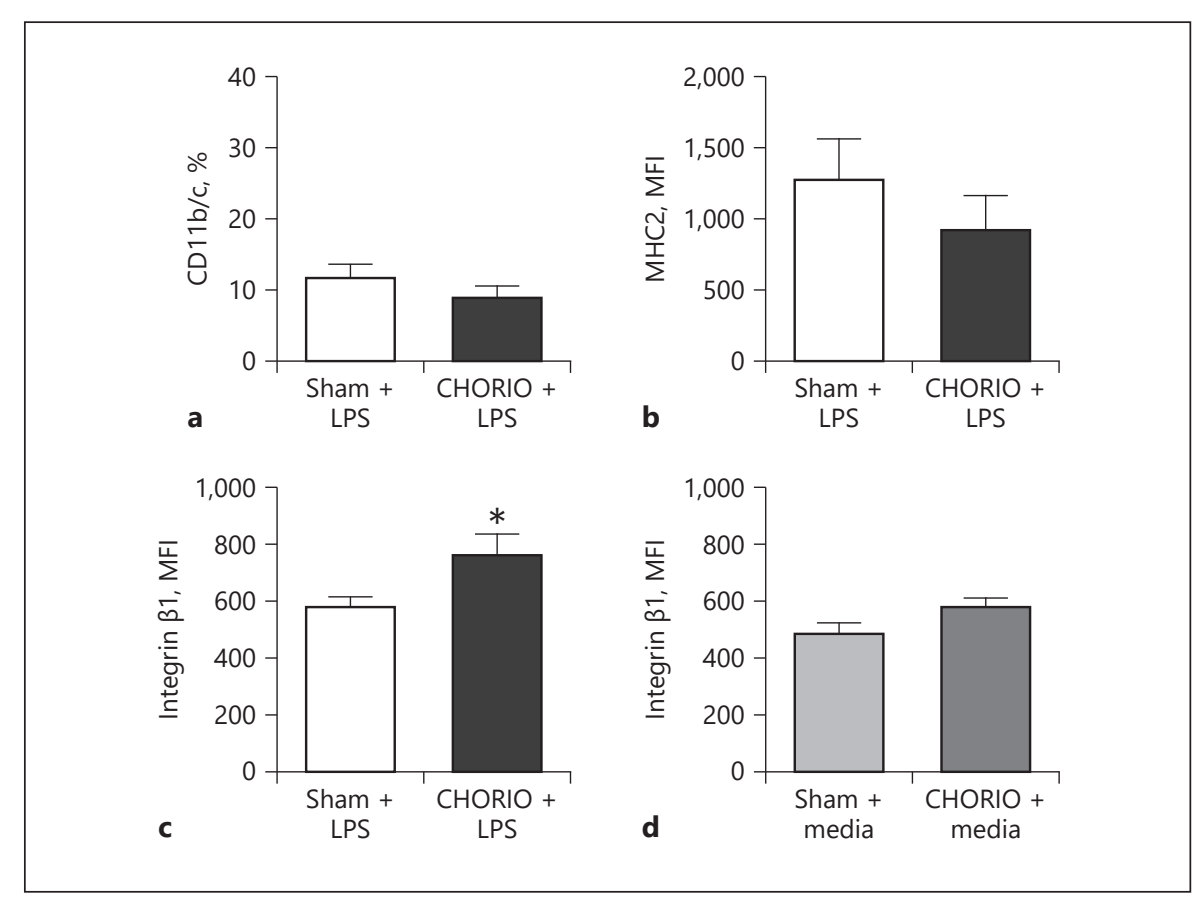

TH1, also secrete TNFa [64]. Previously, we documented transient, acute elevations in TNFa and sustained elevations in CXCL1, a potent neutrophil trafficking chemokine, in the serum of pups with CHORIO $[25,32]$. The mechanism(s) for the elevated serum levels in CHORIO rats may be in part related to the increased secretion of TNF $\alpha$ and CXCL1 from PBMCs, as shown here. Together these data indicate augmented immune function by prior exposure to inflammation during development. Our data are consistent with previous studies in preterm sheep, where responses to LPS in the monocytes of sheep 7-14 days after exposure to intra-amniotic endotoxin tended to exceed those of adults and preterm controls [14, 65]. These data are also consistent with an altered inflammatory cytokine network, hallmarked by increased TNFa and IL-6, in a mouse model of intrauterine infection [64, 66] and a porcine model of maternal infection during pregnancy [67]. Taken together, these data support that the secretion of cytokines and chemokines facilitates a damaging cellular inflammatory response, including the maturation and migration of immune cells.

The underlying causes of altered cellular inflammatory responses in preterm children and those who develop CP remain unknown. While there are many converging genetic and environmental factors that warrant consideration, the increased LPS sensitivity of PBMCs, noted in both children with $\mathrm{CP}$ and our rats exposed to CHORIO, suggests that inflammation during both the perinatal and postnatal periods have a yet-to-be-defined programming effect, yielding a lasting change in immune response. Indeed, neural-immune communication and programming has been reported in several disorders, including chronic pain, fetal alcohol syndrome, stroke, schizophrenia, Alzheimer's disease, and autism spectrum disorders [50, 52, 53, 68-71]. Notably, fetal white blood cell counts change with gestational age, with lymphocytes being the most prevalent leukocyte up to 37 weeks' gestation $[26,72]$. While lymphocytes increase linearly with gestational age, neutrophils increase exponentially after 31 weeks' gestation and become the predominant lymphocyte at term [26]. CHORIO induces circulating CD45RO+ effector/ memory $\mathrm{T}$ cells associated with brain injury in preterm neonates $[20,55]$. Here, we found increased TNFa expression by myeloid cells concomitant with increased $\mathrm{CD} 11 \mathrm{~b} / \mathrm{c}$ cells, a marker of dendritic cells, monocytes, macrophages, and neutrophils, and indicative of hyperimmune activation following LPS stimulation in CHORIO pups. We also observed increased numbers of $\mathrm{CD} 11 \mathrm{~b} / \mathrm{c}$ cells and ED-2/CD163+ macrophages in CHORIO pups alone compared to sham pups in the absence of a second LPS hit. Previously, we reported increased placental and cerebral neutrophils in this model, with elevated CXCR2 and MHC2 expression supporting a global change in immune action following CHORIO. While 
these changes in immune cell composition had normalized by P21, the markers of immune activation, including elevated integrin $\beta 1$ expression, remained in CHORIO PBMCs stimulated with LPS when compared to shamstimulated cells, supporting a persistently increased activation state. Undoubtedly, future investigations must focus on the developmental expression of cytokines, immune markers, and activation states of the circulating and resident leukocyte populations, including neutrophils, as we observed changes in cytokine levels, and leukocyte activation and maturation markers between P7 and P21, with and without additional LPS stimulation.

Understanding the dynamics of altered immune responses and persistent inflammation through the placental-fetal brain axis is a prerequisite for the rational design of therapeutic interventions in this population of vulnerable patients [73]. Lymphocytes are found in the brain after injury in both rodents and humans, and a lack of mature lymphocytes protects from HI-induced whitematter injury [73]. Other groups have shown that a cerebral influx of TH17-like lymphocytes coordinates neuroinflammatory responses, and documented an elevated expression of the early TH17 lymphocyte marker, IL-23R, in PBMCs in infants with confirmed histological CHORIO and in rodents with LPS-sensitized HI injury [20]. Interestingly, in the preclinical rat experiments, administration of FTY720 (fingolimod) blocked leukocyte trafficking and acute induction of NF- $\kappa \beta$ signaling in the developing brain [20], attenuating blood-brain barrier damage and proinflammatory cytokine expression with improved white-matter health [20]. Similarly, ELGAN studies have demonstrated the capacity of infants to respond to in utero inflammation with a proinflammatory TH1/TH17 phenotype [13]. While these responses may be protective against pathogens, they may also promote a sustained fetal and neonatal inflammatory response syn- drome, including SPIHR, which involves multiorgan inflammation and injury $[13,45]$.

In conclusion, this study supports the notion that an inflammatory process that starts in utero may continue through childhood and beyond. Dysfunction throughout the placental-fetal brain axis, including inflammation and HI, may sensitize and program immune cells and associated cytokine networks to respond more vigorously, and for a longer period of time, to a stimulus that would not otherwise have evoked such an intense response [51]. To this end, SPIHR and the activation of immunological memory stemming from in utero insults may be associated with impaired neurodevelopment [55]. The durable changes in PBMC reactivity demonstrated here and elsewhere [14] may prove to be an effective biomarker of perinatal brain injury, and the clinical utility may prove to be high, given the ease of access to these cells and to well-defined stimulation protocols. Additional investigations are required to further understand the homeostatic regulation of central and peripheral inflammatory cells in infants with CHORIO as well as the long-term consequences of its dysregulation.

\section{Acknowledgements}

This study was supported by grants from the National Institutes of Health (HL139492 to LJ; HD086058 to FN) and Dedicated Health Research Funds from the University of New Mexico Department of Pediatrics. The authors are grateful to Dr. Ksenia Matlowska for her expertise and kind assistance with the manuscript.

\section{Statement of Ethics}

The study was performed with the approval of the Institutional Animal Care and Use Committee at the University of New Mexico Health Sciences Center.

\section{References}

1 Kochanek KD, Kirmeyer SE, Martin JA, Strobino DM, Guyer B. Annual summary of vital statistics: 2009. Pediatrics. 2012 Feb; 129(2):338-48

2 Fant ME, Fuentes J, Kong X, Jackman S. The nexus of prematurity, birth defects, and intrauterine growth restriction: a role for plac1regulated pathways. Front Pediatr. 2014 Feb; 2:8.

3 Nosarti C, Reichenberg A, Murray RM, Cnattingius S, Lambe MP, Yin L, et al. Preterm birth and psychiatric disorders in young adult life. Arch Gen Psychiatry. 2012 Jun;69(6):E1-8.
4 Pavlidis E, Lloyd RO, Boylan GB. EEG - A Valuable Biomarker of Brain Injury in Preterm Infants. Dev Neurosci. 2017;39(1-4):2335.

5 Dammann O, Leviton A. Maternal intrauterine infection, cytokines, and brain damage in the preterm newborn. Pediatr Res. 1997 Jul; 42(1): $1-8$.

6 Dammann O, Leviton A. Intermittent or sustained systemic inflammation and the preterm brain. Pediatr Res. 2014 Mar;75(3):37680.
7 Williams M, Zhang Z, Nance E, Drewes JL, Lesniak WG, Singh S, et al. Maternal Inflammation Results in Altered Tryptophan Metabolism in Rabbit Placenta and Fetal Brain. Dev Neurosci. 2017;39(5):399-412.

8 Chau V, McFadden DE, Poskitt KJ, Miller SP. Chorioamnionitis in the pathogenesis of brain injury in preterm infants. Clin Perinatol. 2014 Mar;41(1):83-103.

9 Goldenberg RL, Hauth JC, Andrews WW. Intrauterine infection and preterm delivery. $\mathrm{N}$ Engl J Med. 2000 May;342(20):1500-7. 
10 Lee J, Kim JS, Park JW, Park CW, Park JS, Jun $\mathrm{JK}$, et al. Chronic chorioamnionitis is the most common placental lesion in late preterm birth. Placenta. 2013 Aug;34(8):681-9.

11 Lee SM, Park JW, Kim BJ, Park CW, Park JS, Jun JK, et al. Acute histologic chorioamnionitis is a risk factor for adverse neonatal outcome in late preterm birth after preterm premature rupture of membranes. PLoS One. 2013 Dec;8(12):e79941.

12 Redline RW. Disorders of placental circulation and the fetal brain. Clin Perinatol. 2009 Sep;36(3):549-59.

13 Jackson CM, Wells CB, Tabangin ME, Meinzen-Derr J, Jobe AH, Chougnet CA. Pro-inflammatory immune responses in leukocytes of premature infants exposed to maternal chorioamnionitis or funisitis. Pediatr Res. 2017 Feb;81(2):384-90.

14 Lin CY, Chang YC, Wang ST, Lee TY, Lin CF, Huang CC. Altered inflammatory responses in preterm children with cerebral palsy. Ann Neurol. 2010 Aug;68(2):204-12.

15 Gluckman PD, Hanson MA, Cooper C, Thornburg KL. Effect of in utero and earlylife conditions on adult health and disease. $\mathrm{N}$ Engl J Med. 2008 Jul;359(1):61-73.

16 Redline RW. Correlation of Placental Pathology with Perinatal Brain Injury. Surg Pathol Clin. 2013 Mar;6(1):153-80.

$17 \mathrm{Wu} \mathrm{YW}$. Systematic review of chorioamnionitis and cerebral palsy. Ment Retard Dev Disabil Res Rev. 2002;8(1):25-9.

$18 \mathrm{Wu}$ YW, Colford JM Jr. Chorioamnionitis as a risk factor for cerebral palsy: A meta-analysis. JAMA. 2000 Sep;284(11):1417-24.

19 Wu YW, Escobar GJ, Grether JK, Croen LA, Greene JD, Newman TB. Chorioamnionitis and cerebral palsy in term and near-term infants. JAMA. 2003 Nov;290(20):2677-84.

20 Yang D, Sun YY, Bhaumik SK, Li Y, Baumann JM, Lin X, et al. Blocking lymphocyte trafficking with FTY720 prevents inflammation-sensitized hypoxic-ischemic brain injury in newborns. J Neurosci. 2014 Dec;34(49):16467-81.

21 Pappas A, Kendrick DE, Shankaran S, Stoll BJ, Bell EF, Laptook AR, et al.; Eunice Kennedy Shriver National Institute of Child Health and Human Development Neonatal Research Network. Chorioamnionitis and early childhood outcomes among extremely low-gestational-age neonates. JAMA Pediatr. $2014 \mathrm{Feb}$; 168(2):137-47.

22 Shevell A, Wintermark P, Benini R, Shevell M, Oskoui M. Chorioamnionitis and cerebral palsy: lessons from a patient registry. Eur J Paediatr Neurol. 2014;18:301-7.

23 Galinsky R, Polglase GR, Hooper SB, Black MJ, Moss TJ. The consequences of chorioamnionitis: preterm birth and effects on development. J Pregnancy. 2013;2013:412831.

24 Jantzie LL, Scafidi J, Robinson S. Stem cells and cell-based therapies for cerebral palsy: a call for rigor. Pediatr Res. 2018 Jan;83(1-2): 345-55.

25 Maxwell JR, Denson JL, Joste NE, Robinson S, Jantzie LL. Combined in utero hypoxia-isch- emia and lipopolysaccharide administration in rats induces chorioamnionitis and a fetal inflammatory response syndrome. Placenta. 2015 Dec;36(12):1378-84.

26 Madsen-Bouterse SA, Romero R, Tarca AL, Kusanovic JP, Espinoza J, Kim CJ, et al. The transcriptome of the fetal inflammatory response syndrome. Am J Reprod Immunol. 2010 Jan;63(1):73-92.

27 Gomez R, Romero R, Ghezzi F, Yoon BH, Mazor M, Berry SM. The fetal inflammatory response syndrome. Am J Obstet Gynecol. 1998 Jul;179(1):194-202.

28 Romero R, Gomez R, Ghezzi F, Yoon BH, Mazor M, Edwin SS, et al. A fetal systemic inflammatory response is followed by the spontaneous onset of preterm parturition. Am J Obstet Gynecol. 1998 Jul;179(1):186-93.

29 Claus CP, Tsuru-Aoyagi K, Adwanikar H, Walker B, Manvelyan $\mathrm{H}$, Whetstone W, et al. Age is a determinant of leukocyte infiltration and loss of cortical volume after traumatic brain injury. Dev Neurosci. 2010;32(5-6): 454-65.

30 Jantzie LL, Robinson S. Preclinical Models of Encephalopathy of Prematurity. Dev Neurosci. 2015;37(4-5):277-88.

31 Jantzie LL, Corbett CJ, Berglass J, Firl DJ, Flores J, Mannix R, et al. Complex pattern of interaction between in utero hypoxia-ischemia and intra-amniotic inflammation disrupts brain development and motor function. J Neuroinflammation. 2014 Aug;11(1):131.

32 Yellowhair TR, Noor S, Maxwell JR, Anstine CV, Oppong AY, Robinson S, et al. Preclinical chorioamnionitis dysregulates CXCL1/ CXCR2 signaling throughout the placentalfetal-brain axis. Exp Neurol. 2018 Mar;301(Pt B):110-19

33 Jantzie LL, Oppong AY, Conteh FS, Yellowhair TR, Kim J, Fink G, et al. Extended neonatal erythropoietin and melatonin combinatorial treatment provides enduring repair of functional deficits in a rat model of cerebral palsy. Front Neurol. 2018 Apr;9:233.

34 Kilkenny C, Browne WJ, Cuthill IC, Emerson $\mathrm{M}$, Altman DG. Improving bioscience research reporting: the ARRIVE guidelines for reporting animal research. PLoS Biol. 2010 Jun;8(6):e1000412.

35 Jantzie LL, Corbett CJ, Firl DJ, Robinson S. Postnatal Erythropoietin Mitigates Impaired Cerebral Cortical Development Following Subplate Loss from Prenatal Hypoxia-Ischemia. Cereb Cortex. 2015 Sep;25(9):2683-95.

36 Jantzie LL, Getsy P, Denson JL, Firl DJ, Wilson CG, Robinson S. Prenatal hypoxia-ischemia induces potassium chloride cotransporter 2 loss and abnormalities in inhibitory tone. Front Cell Neurosci. 2015;3:347.

37 Jantzie LL, Getsy PM, Firl DJ, Wilson CG, Miller RH, Robinson S. Erythropoietin attenuates loss of potassium chloride co-transporters following prenatal brain injury. Mol Cell Neurosci. 2014 Jul;61:152-62.

38 Jantzie LL, Miller RH, Robinson S. Erythropoietin signaling promotes oligodendrocyte development following prenatal systemic hypoxic-ischemic brain injury. Pediatr Res. 2013 Dec;74(6):658-67.

39 Kowalski ML, Wolska A, Grzegorczyk J, Hilt J, Jarzebska M, Drobniewski M, et al. Increased responsiveness to toll-like receptor 4 stimulation in peripheral blood mononuclear cells from patients with recent onset rheumatoid arthritis. Mediators Inflamm. 2008;2008: 132732 .

40 Shiratori H, Feinweber C, Luckhardt S, Linke B, Resch E, Geisslinger G, et al. THP-1 and human peripheral blood mononuclear cellderived macrophages differ in their capacity to polarize in vitro. Mol Immunol. 2017 Aug; 88:58-68.

41 Ayer JG, Song C, Steinbeck K, Celermajer DS, Ben Freedman S. Increased tissue factor activity in monocytes from obese young adults. Clin Exp Pharmacol Physiol. 2010 Nov; 37(11):1049-54.

42 Hally KE, La Flamme AC, Harding SA, Larsen $\mathrm{PD}$. Platelets regulate leucocyte responses to Toll-like receptor stimulation. Clin Transl Immunology. 2018 Jul;7(7):e1036.

43 Robinson S, Corbett CJ, Winer JL, Chan LA, Maxwell JR, Anstine CV, et al. Neonatal erythropoietin mitigates impaired gait, social interaction and diffusion tensor imaging abnormalities in a rat model of prenatal brain injury. Exp Neurol. 2018 Apr;302:1-13.

44 Robinson S, Winer JL, Berkner J, Chan LA, Denson JL, Maxwell JR, et al. Imaging and serum biomarkers reflecting the functional efficacy of extended erythropoietin treatment in rats following infantile traumatic brain injury. J Neurosurg Pediatr. 2016 Jun;17(6): 739-55.

45 Dammann O, Allred EN, Fichorova RN, Kuban K, O'Shea TM, Leviton A; ELGAN Study Investigators. Duration of Systemic Inflammation in the First Postnatal Month Among Infants Born Before the 28th Week of Gestation. Inflammation. 2016 Apr;39(2): 672-7.

46 Kuban KC, O'Shea TM, Allred EN, Fichorova RN, Heeren T, Paneth N, et al.; ELGAN Study Investigators. The breadth and type of systemic inflammation and the risk of adverse neurological outcomes in extremely low gestation newborns. Pediatr Neurol. 2015 Jan; 52(1):42-8.

47 Leviton A, Kuban KC, Allred EN, Fichorova RN, O'Shea TM, Paneth N; ELGAN Study Investigators. Early postnatal blood concentrations of inflammation-related proteins and microcephaly two years later in infants born before the 28th post-menstrual week. Early Hum Dev. 2011 May;87(5):325-30.

48 O'Shea TM, Allred EN, Kuban KC, Dammann O, Paneth N, Fichorova R, et al. Extremely Low Gestational Age Newborn Study I: Elevated concentrations of inflammationrelated proteins in postnatal blood predict severe developmental delay at 2 years of age in extremely preterm infants. J Pediatr. 2012; 160:395-401. 
49 Schuerwegh AJ, Stevens WJ, Bridts CH, De Clerck LS. Evaluation of monensin and brefeldin A for flow cytometric determination of interleukin-1 beta, interleukin-6, and tumor necrosis factor-alpha in monocytes. $\mathrm{Cy}$ tometry. 2001 Jun;46(3):172-6.

50 Noor S, Sanchez JJ, Vanderwall AG, Sun MS, Maxwell JR, Davies S, et al. Prenatal alcohol exposure potentiates chronic neuropathic pain, spinal glial and immune cell activation and alters sciatic nerve and DRG cytokine levels. Brain Behav Immun. 2017 Mar;61:80-95.

51 Yanni D, Korzeniewski SJ, Allred EN, Fichorova RN, O'Shea TM, Kuban K, et al. Both antenatal and postnatal inflammation contribute information about the risk of brain damage in extremely preterm newborns. Pediatr Res. 2017 Oct;82(4):691-6.

52 Bilbo SD, Biedenkapp JC, Der-Avakian A, Watkins LR, Rudy JW, Maier SF. Neonatal infection-induced memory impairment after lipopolysaccharide in adulthood is prevented via caspase-1 inhibition. J Neurosci. 2005 Aug;25(35):8000-9.

53 Bilbo SD, Levkoff LH, Mahoney JH, Watkins LR, Rudy JW, Maier SF. Neonatal infection induces memory impairments following an immune challenge in adulthood. Behav Neurosci. 2005 Feb;119(1):293-301.

54 Leviton A, Kuban K, O'Shea TM, Paneth N, Fichorova R, Allred EN, et al. The relationship between early concentrations of 25 blood proteins and cerebral white matter injury in preterm newborns: the ELGAN study. J Pediatr. 2011;158:897-903.

55 Duggan PJ, Edwards AD. Placental inflammation and brain injury in preterm infants. Dev Med Child Neurol Suppl. 2001 Mar;86: 16-17.

56 Duggan PJ, Maalouf EF, Watts TL, Sullivan $\mathrm{MH}$, Counsell SJ, Allsop J, et al. Intrauterine T-cell activation and increased proinflammatory cytokine concentrations in preterm infants with cerebral lesions. Lancet. 2001 Nov: 358(9294):1699-700
57 Tsukimori K, Komatsu H, Yoshimura T, Hikino S, Hara T, Wake N, et al. Increased inflammatory markers are associated with early periventricular leukomalacia. Dev Med Child Neurol. 2007 Aug;49(8):587-90.

58 Yoon BH, Jun JK, Romero R, Park KH, Gomez R, Choi JH, et al. Amniotic fluid inflammatory cytokines (interleukin-6, interleukinlbeta, and tumor necrosis factor-alpha), neonatal brain white matter lesions, and cerebral palsy. Am J Obstet Gynecol. 1997 Jul;177(1): 19-26.

59 Kaukola T, Satyaraj E, Patel DD, Tchernev VT, Grimwade BG, Kingsmore SF, et al. Cerebral palsy is characterized by protein mediators in cord serum. Ann Neurol. 2004 Feb; 55(2):186-94.

60 Anthony D, Dempster R, Fearn S, Clements J, Wells G, Perry VH, et al. CXC chemokines generate age-related increases in neutrophilmediated brain inflammation and bloodbrain barrier breakdown. Curr Biol. 1998 Jul; 8(16):923-6.

61 Fernández-López D, Faustino J, Daneman R, Zhou L, Lee SY, Derugin N, et al. Blood-brain barrier permeability is increased after acute adult stroke but not neonatal stroke in the rat. J Neurosci. 2012 Jul;32(28):9588-600.

62 Wang LY, Tu YF, Lin YC, Huang CC. CXCL5 signaling is a shared pathway of neuroinflammation and blood-brain barrier injury contributing to white matter injury in the immature brain. J Neuroinflammation. 2016 Jan; 13(1):6.

63 Chao CC, Hu S, Sheng WS, Peterson PK. Tumor necrosis factor-alpha production by human fetal microglial cells: regulation by other cytokines. Dev Neurosci. 1995;17(2):97-105.

64 Su X, Yuan H, Cui H, Zhu H, Yun X, Tang W, et al. Effect of T helper cell $1 / \mathrm{T}$ helper cell 2 balance and nuclear factor- $\kappa \mathrm{B}$ on white matter injury in premature neonates. Mol Med Rep. 2018 Apr;17(4):5552-6.

65 Kramer BW, Ikegami M, Moss TJ, Nitsos I, Newnham JP, Jobe AH. Endotoxin-induced chorioamnionitis modulates innate immunity of monocytes in preterm sheep. Am J Respir Crit Care Med. 2005 Jan;171(1):73-7.
66 Anand G, Vasanthakumar R, Mohan V, Babu $\mathrm{S}$, Aravindhan V. Increased IL-12 and decreased IL-33 serum levels are associated with increased Th1 and suppressed Th2 cytokine profile in patients with diabetic nephropathy (CURES-134). Int J Clin Exp Pathol. 2014 Oct;7(11):8008-15.

67 Antonson AM, Balakrishnan B, Radlowski EC, Petr G, Johnson RW. Altered Hippocampal Gene Expression and Morphology in Fetal Piglets following Maternal Respiratory Viral Infection. Dev Neurosci. 2018;40(2):104-19.

68 Vanderwall AG, Noor S, Sun MS, Sanchez JE, Yang XO, Jantzie LL, et al. Effects of spinal non-viral interleukin-10 gene therapy formulated with d-mannose in neuropathic interleukin-10 deficient mice: behavioral characterization, mRNA and protein analysis in pain relevant tissues. Brain Behav Immun. 2018 Mar;69:91-112.

69 Noor S, Milligan ED. Lifelong Impacts of Moderate Prenatal Alcohol Exposure on Neuroimmune Function. Front Immunol. 2018 May;9:1107.

70 Vargas DL, Nascimbene C, Krishnan C, Zimmerman AW, Pardo CA. Neuroglial activation and neuroinflammation in the brain of patients with autism. Ann Neurol. 2005 Jan; 57(1):67-81.

71 Jyonouchi H, Sun S, Le H. Proinflammatory and regulatory cytokine production associated with innate and adaptive immune responses in children with autism spectrum disorders and developmental regression. J Neuroimmunol. 2001 Nov;120(1-2):170-9.

72 Davies NP, Buggins AG, Snijders RJ, Jenkins E, Layton DM, Nicolaides KH. Blood leucocyte count in the human fetus. Arch Dis Child. 1992 Apr;67(4 Spec No):399-403.

73 Nazmi A, Albertsson AM, Rocha-Ferreira E Zhang X, Vontell R, Zelco A, et al. Lymphocytes Contribute to the Pathophysiology of Neonatal Brain Injury. Front Neurol. 2018 Mar;9:159.
Chorioamnionitis and Persistent

Lymphocyte Reactivity
Dev Neurosci 2018;40:523-533

DOI: $10.1159 / 000497273$ 